\title{
Rituximab in ANA positive polyarticular juvenile idiopathic arthritis (JIA) with uveitis
}

\section{EM Baildam* and S Saladi}

Address: Royal Liverpool Children's Hospital, Mersey, UK

* Corresponding author

from $15^{\text {th }}$ Paediatric Rheumatology European Society (PreS) Congress

London, UK. 14-17 September 2008

Published: 15 September 2008

Pediatric Rheumatology 2008, 6(SuppI I):P7I doi:I0.II86/I546-0096-6-SI-P7I

This abstract is available from: http://www.ped-rheum.com/content/6/SI/P7I

(C) 2008 Baildam and Saladi; licensee BioMed Central Ltd.

We report the case of a 15 year old girl with an 8 year history of difficult to control polyarticular ANA +ve, RF -ve, JIA with severe right sided uveitis treated with Rituximab based on the NICE approved regime for adult rheumatoid arthritis.

She presented at the age of 7 years with a 6 week history of painful arthritis involving both ankles, knees, left elbow and left middle PIP joints. Subsequently there was progression to include wrists, TMJs, with erosive disease in both hips and ankles, and intermittent wheelchair use. She was treated with $15-20 \mathrm{mg} / \mathrm{m}^{2}$ of Methotrexate, tried on full dose Etanercept for 12 months, then Infliximab for 6 months, followed by Adalimumab for 6 months. Ciclosporine was added for a 3 DMARD approach but stopped due to hypertension. Throughout she always required additional multiple intra-articular steroid injections and methlyprednisolone infusions (and topical Pred Forte eye drops) to maintain her in reasonable remission. After much consideration she was treated with Rituximab 1 gm by intravenous infusion repeated 2 weeks later and sub-cutaneous methotrexate continued. Since then she has remained in arthritis free remission for 7 months but her uveitis is unchanged in severity. CHAQ scores fell from 1.5 pre-treatment to 0.4 post treatment and active joint counts fell from 5 to 0 . Rituximab may be useful in polyarticular JIA resistant to anti-TNF therapy and we recommend a drug trial for this small group of patients.

\section{References}

I. Cohen SB, Emery P, Greenwald MW, Dougados M, Furie RA, Genovese MC, Keystone EC, Loveless JE, Burmester G-R, Cravets MW,
Hessey EW, Shaw T, Totoritis MC, for the REFLEX Trial Group: Rituximab for rheumatoid arthritis refractory to anti-tumor necrosis factor therapy. Arthritis Rheum 2006, 54:2793-2806.

2. TAI 26 Rheumatoid arthrits (refractory) - rituximab: Guidance NICE 22.08.07. 